\title{
A Note on Citations and Translations
}

All citations from the Commedia are from Singleton's version of the Petrocchi text as published in The Divine Comedy, translation and commentary by Charles S. Singleton (Princeton, N.J.: Princeton University Press, I97075). Translations from the Latin Vulgate Bible are adapted with minor modifications from the Douay/Rheims edition. Texts and translations of Virgil and Ovid are from the Loeb Library editions. Translations of other works listed in original-language versions in the bibliography are my own unless otherwise noted. 

Dante's Testaments 
